\section{High Competence for Adventitious Regeneration in the BU-21/3 Melon Genotype Is Controlled by a Single Dominant Locus}

\author{
Marjana Galperin \\ Faculty of Life Sciences, Bar Ilan University, Ramat Gan, 52900 Israel
}

\author{
Aaron Zelcer \\ Department of Plant Genetics, Agricultural Research Organization, POB 6 , \\ Bet-Dagan, 50250 Israel \\ David Kenigsbuch ${ }^{1}$ \\ Department of Postharvest Science of Fresh Produce, Agricultural Research \\ Organization, POB 6, Bet-Dagan, 50250 Israel
}

Additional index words. Cucumis melo, organogenesis, reticulatus

Abstract. BU-21/3 is an inbred melon (Cucumis melo L.) genotype that exhibits superior in vitro capabilities for adventitious organogenesis. In order to characterize the inheritance of the regeneration competence in BU-21/3, this line was crossed with PMR45 or 'Ananas-Yokneam' - two reticulatus cultivars virtually incompetent for organogenesis. F1, F2, and backcross generations were produced and evaluated for adventitious regeneration competence. Our results indicate that the regeneration trait in $\mathrm{BU}-21 / 3$ is controlled by a single dominant locus, without cytoplasmic interactions. This locus may become a valuable tool for imperative improvements in future protocols for transgenic breeding of commercial melon genotypes.

The induction of organogenetic or embryogenetic regeneration in melon has been the subject of numerous studies. Regeneration efficiency is strongly affected by the explant source, media composition, and physical factors, as recently reviewed (Guis et al., 1998). It is often difficult to reconcile contradictory reports concerning the efficiency of adventitious regeneration in this species. While successful regeneration was seen in some genotypes (Kathal et al., 1986; Tabei et al., 1991; Yadav et al., 1996), poor regeneration occurred with others (Gaba et al., 1999; Liborio-Stipp et al., 2001). Moreover, regeneration may even vary among plants or seed lots of the same genotype (Molina and Nuez, 1995; Orts et al., 1987). Differences in ability for organogenesis/embryogenesis were detected between reticulatus and inodorus melon subgenera. Reticulatus genotypes excel in embryogenesis (Gray et al., 1993; Oridate et al., 1992) while inodorus cultivars show a uniformly higher organogenesis rate (Ficcadenti and Rotino, 1995). The involvement of two partially dominant loci in determining differences in the organogenic competence of a segregating melon population was suggested (Molina and Nuez, 1996). The sexual transmission of this regeneration trait to the selfed progeny of competent segregants from this population was demonstrated (Molina and Nuez, 1997). Likewise, the feasibility for sex-

Received for publication 3 June 2002. Accepted for publication 13 Jan. 2003

${ }^{1}$ To whom reprint requests should be addressed. E-mail: davke@agri.gov.il; fax +972-3-9683622. ual transfer of the embryogenic potential from superior to nonresponsive cultivars confirmed that this trait is under genetic control (Oridate et al., 1992). We report herein our results on the inheritance of the regeneration competence in BU-21/3, an inbred melon genotype that exhibits superior in vitro capabilities for adventitious organogenesis. A detailed description of the identification and characterization of this line was included elsewhere (Galperin et al., 2003).

The BU-21/3 line was crossed with two reticulatus genotypes: PMR45, a commercial American cantaloupe cultivar, or with 'AnanasYokneam' (AY), a local commercial cultivar. This latter lines were chosen as the counterpart (PMR45 or AY) lines. for $\mathrm{BU}-21 / 3$ since their regeneration is arrested at the callusing stage, and no bud initials or primordia were normally discernible in cultured explants. F1, F2, and backcross generations were produced and evaluated for adventitious regeneration competence.

Adventitious regeneration in melon was induced as described by Fang and Grumet (1990), with some modifications. De-coated and surface-sterilized seeds were incubated for $2 \mathrm{~d}$ on solidified MS medium (Murashige and Skoog, 1962), containing 3\% sucrose. The basal end of the seed (containing the embryo) was removed, and individual cotyledons were dissected into four explants. One explant per seed was utilized in the genetic experiments. Explants (8-10 explants/plate) were incubated on regeneration medium (solidified MS medium $+3 \%$ sucrose $+1 \mathrm{mg} \cdot \mathrm{L}^{-1}$ benzylaminopurine (BAP). Regenerated shoots were transferred to elongation medium - identical to the regeneration medium except for a reduced $\left(0.05 \mathrm{mg} \cdot \mathrm{L}^{-1}\right)$ BAPconcentration. Shoots were then transferred to rooting medium [solidified $\mathrm{MS}+2 \%$ sucrose $+0.1 \mathrm{mg} \cdot \mathrm{L}^{-1}$ indoleacetic acid (IAA)]. Throughout all stages, cultures were maintained under a $16-\mathrm{h}$ photoperiod (fluorescent illumination, $125 \mu \mathrm{E} \cdot \mathrm{m}^{-2} \cdot \mathrm{s}^{-1}$ ) at 25 ${ }^{\circ} \mathrm{C}$. Regeneration competence of individual explants was determined 7 weeks after beginning of culturing. Explants exhibiting any number of shoots were classified as "regenerating."

Table 1 provides data on the mode of inheritance of the regeneration competence trait in crosses between BU-21/3 and the two noncompetent cultivars PMR45 or AY. The data summarize the result of one experiment for each noncompetent parent in which all the respective generations were evaluated simultaneously under the same culture conditions. Explants from F1, F2, and backcross populations exhibited either a highly regenerating phenotype (similar to the BU-21/3 parent) or a nonregenerating phenotype (similar to the noncompetent parent). F1 reciprocal crosses (BU-21/3 x PMR45) behaved similarly to the competent line (BU-21/3), indicating the dominance of this trait and the lack of cytoplasmic interactions (Table 1A). The F2 populations segregate at a 3:1 ratio, suggesting that the

Table 1. Inheritance of the regeneration trait in crosses between competent (BU-21/3) and noncompetent

\begin{tabular}{|c|c|c|c|c|c|}
\hline \multicolumn{6}{|c|}{ A. BU-21/3 x PMR45 } \\
\hline Genotype/cross & Regenerating explants & Nonregenerating explants & Ratio & $\chi^{2}$ & $P$ \\
\hline$\overline{\mathrm{BU}}-21 / 3(\mathrm{P} 1)$ & 69 & 1 & & & \\
\hline PMR45 (P2) & 0 & 34 & & & \\
\hline F1-P1 fem ${ }^{2}$ & 37 & 0 & & & \\
\hline F1-P2 fem ${ }^{2}$ & 29 & 2 & & & \\
\hline $\mathrm{F} 2$ & 120 & 46 & $3: 1$ & 0.65 & 0.42 \\
\hline BCP1 & 62 & 2 & & & \\
\hline $\mathrm{BCP} 2$ & 28 & 40 & $1: 1$ & 2.19 & 0.15 \\
\hline
\end{tabular}

${ }^{\mathrm{z}} \mathrm{F} 1$ reciprocal crosses in which $\mathrm{P} 1$ or $\mathrm{P} 2$ served as the female parent, respectively.

\begin{tabular}{lccccc} 
B. BU-21/3 x AY & & & & \\
Genotype/cross & Regenerating explants & Nonregenerating explants & Ratio & $\chi^{2}$ & $P$ \\
\hline BU-21/3 (P1) & 45 & 1 & & & \\
AY (P2) & 0 & 42 & & & \\
F1-P1 fem & 40 & 3 & $3: 1$ & 2.2 & 0.157 \\
F2 & 154 & 64 & & & \\
BCP1 & 70 & 6 & $1: 1$ & 0.59 & 0.442 \\
BCP2 & 38 & 45 & & \\
\hline
\end{tabular}


regeneration trait is controlled by a single locus. Aconfirmation to this observation was obtained from the backcross populations between the F1 and either parent. Backcross to the regeneration competent parent resulted in virtually fully competent progeny, while backcross to the noncompetent parent yielded a population segregating at a 1:1 ratio (Table $1 \mathrm{~A}, 1 \mathrm{~B})$. Noteworthy, a similar range of regeneration was observed in responsive explants from BU-21/3, F1, F2, or backcross populations with either of the nonresponsive parents.

In a similar study, differences in regeneration potential between individuals from a heterogeneous 'Cantaloupe Charentais' melon cultivar were assigned to the presence of two partially dominant genes (Molina and Nuez, 1996). Presumably, the regeneration response is a complex developmental process requiring the involvement of many genes. We lack data to discard any possible allelism between the regeneration competence trait from BU-21/3 and the loci described by Molina and Nuez (1996). However, we should stress that the parental genotypes described in the present work exhibit two extreme responses (either highly regenerating or nonregenerating), in contrast with the narrower quantitative differences exhibited by the parental lines in the work cited above.

In spite of many efforts invested in transgenic breeding of melon, many commercial cultivars are not amenable for this application due to a low efficiency of regeneration or trans- formation (Guis et al., 1998). We therefore are presently interested in introgressing the regeneration-competence trait into elite commercial cultivars, to seek for eventual improvements in the transformation capabilities of genotypes with superior horticultural background.

\section{Literature Cited}

Fang, G. and R. Grumet. 1990. Agrobacterium tumefaciens mediated transformation and regeneration of muskmelon plants. Plant Cell Rpt. 9:160-164.

Ficcadenti, N. and G.L. Rotino. 1995. Genotype and medium affect shoot regeneration of melon. Plant Cell Tiss. Organ Cult. 40:293-295.

Gaba, V., E. Schlarman, C. Elman, O. Sagee, A.A. Watad, and D.J. Gray. 1999. In vitro studies on the anatomy and morphology of bud regeneration in melon cotyledons. In Vitro Cell Dev. Biol. Plant 35:1-7.

Galperin, M., L. Patlis, A. Ovadia, D. Wolf, A. Zelcer, and D. Kenigsbuch. 2003. A melon genotype with superior competence for regeneration and transformation. Plant Breeding 122:66-69.

Gray, D.J., D. W. McColley, and M.E. Compton. 1993. High-frequency somatic embryogenesis from quiescent seed cotyledons of Cucumis melo cultivars. J. Amer. Soc. Hort. Sci. 118: 425-432.

Guis, M., J.P. Roustan, C. Dogimont, M. Pitrat, and J.C. Pech.1998. Melon biotechnology. Biotechnol. Gen. Eng. Rev. 15:289-311.

Kathal, R., S.P. Bhatnagar, and S.S. Bhojwani. 1986. Regeneration of shoots from hypocotyl callus of Cucumis melo cv. Pusa Sharbati. J. Plant
Physiol. 126:59-62.

Liborio-Stipp, L.C., B.M. Januzzi-Mendes, S.M.D. Stefano-Piedade, and A.P. Martinelli-Rodriguez. 2001. In vitro morphogenesis of Cucumis melo var. inodorus. Plant Cell Tiss. Org. Cult. 65: 81-89.

Molina, R.V. and F. Nuez. 1995. Characterization and classification of different genotypes in a population of Cucumis melo based on their ability to regenerate shoots from leaf explants. Plant Cell Tiss. Org. Cult. 43:249-257.

Molina, R.V. and F. Nuez. 1996. The inheritance of organogenic response in melon. Plant Cell Tiss. Organ Cult 46:251-256.

Molina, R.V. and F. Nuez.1997. Sexual transmission of the in vitro regeneration capacity via caulogenesis of Cucumis melo $\mathrm{L}$. in a medium with a high auxin/cytokinin ratio. Sci. Hort. 70: 237-241.

Murashige, T. and F. Skoog. 1962. Arevised medium for rapid growth and bioassays with tobacco tissue cultures. Physiol. Plant 15:473-497.

Oridate, T., H. Atsumi, S. Ito, and H. Araki. 1992. Genetic difference in somatic embryogenesis from seeds in melon (Cucumis melo L.). Plant Cell Tiss. Org. Cult. 29:27-30.

Orts, M.C., B. Garcia-Sogo, M.V. Roche, L.A. Roig, and V. Moreno . 1987. Morphogenetic response of calli derived from primary explants of diverse cultivars of melon. HortScience 22:666.

Tabei, Y., T. Kanno, and T. Nishio. 1991. Regulation of organogenesis and somatic embryogenesis by auxin in melon, Cucumis melo L. Plant Cell Rpt. 10:225-229.

Yadav, R.C., M.T. Saleh, and R. Grumet. 1996. High frequency shoot regeneration from leaf explants of muskmelon. Plant Cell Tiss. Org. Cult. 45:207-214. 